\title{
ОЦЕНКА ВЛИЯНИЯ ИНВЕСТИЦИОННЫХ И ИННОВАЦИОННЫХ ФАКТОРОВ НА УРОВЕНЬ СОЦИАЛЬНО-ЭКОНОМИЧЕСКОГО РАЗВИТИЯ РЕГИОНА
}

\section{ASSESSMENT OF THE IMPACT OF INVESTMENT AND INNOVATION FACTORS ON THE LEVEL OF SOCIO-ECONOMIC DEVELOPMENT OF THE REGION}

V. Shapovalova

Summary: The article selects investment and innovation factors that influence one of the indicators of socio-economic development of the region. A correlation-regression model is constructed. It is used to assess the impact of investment and innovation factors on the level of socioeconomic development of the region. The Nizhny Novgorod region is taken as the study region. The model reveals the degree of influence of the identified factors on the level of socio-economic development of the Nizhny Novgorod region.

Keywords: correlation analysis, innovations, investments, socio-economic development.

\author{
Шаповалова Вера Николаевна \\ К.э.н., дочент, Российская таможенная академия \\ gorchakmarina@mail.ru
}

Аннотация: В статье проведен отбор инвестиционных и инновационных факторов, оказывающих влияние на один из показателей социально экономического развития региона. Построена корреляционно-регрессионная модель. С ее помощью оценивается влияние инвестиционных и инновационных факторов на уровень социально-экономического развития региона. В качестве исследуемого региона берется Нижегородская область. Модель выявляет степень влияния выявленных факторов на уровень социальноэкономического развития Нижегородской области.

Ключевые слова: корреляционный анализ, инновации, инвестиции, социально-экономическое развитие.

Для наиболее точного анализа и отбора инвестиционных и инновационных факторов, оказывающих наибольшее влияние на уровень социально-экономического развития, проведем корреляционно-регрессионный анализ для Нижегородской области и Приволжского федерального округа в целом.

Проведем отбор инвестиционных факторов, оказывающих наибольшее влияние на уровень ВРП на душу населения Нижегородской области и ПФО.

В таблице 1 представлена динамика значений результативного показателя и инвестиционных факторов Нижегородской области и ПФО за период с 2011 по 2018 гг.

Как можно заметить по таблице, объем ВРП на душу населения, как по Нижегородской области, так и по ПФО в целом имел тенденцию к увеличению. Динамика всех показателей инвестиционного развития в течение рассматриваемого периода была различна.

Результаты корреляционного анализа для выявления тесноты связи между инвестиционными факторами региона и уровнем ВРП на душу населения Нижегородской области и ПФО представлены в таблице 2. 
Динамика значений результативного показателя и инвестиционных факторов Нижегородской области и ПФО за период с 2011 по 2019 гг. (составлено автором)

\begin{tabular}{|c|c|c|c|c|c|c|c|c|}
\hline \multirow[t]{2}{*}{ Год } & \multicolumn{2}{|c|}{ ВРП на душу населения, руб. Ү } & \multicolumn{2}{|c|}{$\begin{array}{c}\text { Инвестиции в основной капитал } \\
\text { на душу населения, руб. } \\
\text { X1 }\end{array}$} & \multicolumn{2}{|c|}{$\begin{array}{c}\text { Сумма поступивших иностранных } \\
\text { инвестиций на душу населения, } \\
\text { долл. США, } \\
\text { Х2 }\end{array}$} & \multicolumn{2}{|c|}{$\begin{array}{c}\text { Сумма изъятых иностранных } \\
\text { инвестиций на душу населе- } \\
\text { ния, долл. США, } \\
\text { ХЗ }\end{array}$} \\
\hline & $\begin{array}{c}\text { Нижегород- } \\
\text { ская обл. }\end{array}$ & ПФ0 & $\begin{array}{c}\text { Нижегород- } \\
\text { ская обл. }\end{array}$ & ПФ0 & $\begin{array}{c}\text { Нижегород- } \\
\text { ская обл. }\end{array}$ & ПФ0 & $\begin{array}{c}\text { Нижегород- } \\
\text { ская обл. }\end{array}$ & ПФ0 \\
\hline 2011 & 196792,5 & 236240 & 57901,0 & 61565 & 351,1 & 168,06 & 213,8 & 196,91 \\
\hline 2012 & 255722,7 & 263976 & 67938,0 & 57044 & 300,0 & 176,41 & 200,3 & 142,45 \\
\hline 2013 & 281581,1 & 284810 & 72991,0 & 64340 & 318,5 & 199,60 & 126,5 & 142,14 \\
\hline 2014 & 308152,1 & 308995 & 75173,0 & 80208 & 325,6 & 169,14 & 280,1 & 178,60 \\
\hline 2015 & 338304,4 & 339075 & 71991,0 & 82956 & 288,5 & 220,93 & 212,3 & 250,59 \\
\hline 2016 & 356725,8 & 348227 & 73300,0 & 82215 & 218,3 & 193,07 & 168,4 & 102,81 \\
\hline 2017 & 388808,8 & 372654 & 76671,0 & 82084 & 224,4 & 215,98 & 251,9 & 91,63 \\
\hline 2018 & 410365,0 & 392652 & 80332,0 & 83738 & 250,5 & 230,36 & 233,3 & 201,04 \\
\hline
\end{tabular}

Таблица 2

Результаты корреляционного анализа тесноты связи между инвестиционными факторами и ВРП на душу населения Нижегородской области и ПФО (составлено автором)

\begin{tabular}{|c|c|c|c|}
\hline Регион & $\begin{array}{c}\text { Инвестиции в основной капитал } \\
\text { на душу населения, руб. } \\
\text { Х1Y }\end{array}$ & $\begin{array}{c}\text { Сумма поступивших иностранных инве- } \\
\text { стиций на душу населения, долл. США, } \\
\text { Х2Y }\end{array}$ & $\begin{array}{c}\text { Сумма изъятых иностранных инвести- } \\
\text { ций на душу населения, долл. США, } \\
\text { Х3Ү }\end{array}$ \\
\hline Нижегородская область & 0,905 & $-0,845$ & 0,254 \\
\hline ПФО & 0,890 & 0,820 & $-0,105$ \\
\hline
\end{tabular}

Корреляционный анализ данных факторов показал, что ВРП на душу населения Нижегородской области имеет прямую тесную связь с инвестициями в основной капитал на душу населения $\left(r_{y \times 1}=0,905\right)$, а также существенную обратную связь с поступившими в регион иностранными инвестициями $\left(r_{y \times 2}=-0,845\right)$. Фактор X3 имеет слабую прямую связь с зависимой переменной $\left(r_{y \times 3}=0,254\right)$, а значит - данный фактор не оказывает значительного влияния на ВРП на душу населения, как на один из показателей социально-экономического развития региона. Поэтому данный фактор нецелесообразно использовать в модели регрессии.

ВРП на душу населения ПФО имеет прямую тесную связь с инвестициями в основной капитал на душу населения $\left(r_{y x 1}=0,890\right)$, а также с поступившими иностранными инвестициями $\left(r_{y x 2}=0,820\right)$. С изъятыми из ПФО иностранными инвестициями $\left(r_{y х 3}=-0,105\right)$ результативный показатель имеет слабую обратную связь. Данный фактор не оказывает значительного влияния на ВРП на душу населения, как на один из показателей социальноэкономического развития, поэтому его нецелесообразно включать в модель регрессии.

Оценим значимость модели регрессии и ее параме- тров для Приволжского федерального округа. Статистическая значимость уравнения регрессии определяется с помощью F-критерия Фишера. $F_{\text {крит }}=(0,05 ; 2 ; 8-2-1)=5,79$. В данном случае $F_{\text {расч }}(37,08)>F_{\text {крит }}(5,79)$, поэтому уравнение регрессии является значимым.

Для оценки значимости параметров уравнения регрессии используется расчет t-критерия Стьюдента. В данном случае: $t_{\text {крит }}=(0,05 ; 8-2-1)=2,57, t_{|a 1|}=4,19 t_{|a 2|}=3,05$. Так как $t_{a 1}>t_{\text {крит' }} t_{\text {a2 }}>t_{\text {крит, }}$ то параметры $a_{1}, a_{2}$ являются статистически значимыми, а это значит, что их можно включить в модель линейной регрессии.

Зависимость между ВРП на душу населения Нижегородской области и инвестиционными факторами выражается уравнением регрессии:

$$
Y_{\text {Ниж. }}=34903,5+6,5^{*} x_{1}-652,9^{*} x_{2} \text {, }
$$

где $Y_{\text {ниж. }}$ ВРП на душу населения Нижегородской области, рублей;

$x_{1}$ - Инвестиции в основной капитал на душу населения, рублей;

$x_{2}$ - Сумма поступивших иностранных инвестиций на душу населения в Нижегородскую область, долл. США. 
Оценим значимость модели и ее параметров. Уравнение регрессии является значимым, так как $F_{\text {расч }}(25,62)$ $>F_{\text {крит }}(5,79)$. Параметры $a_{1}, a_{2}$ являются статистически значимыми и могут быть включены в модель линейной регрессии, так как $t_{a 1}(3,67)>t_{\text {крит }}(2,57), t_{\text {a2 }}(2,58)>t_{\text {крит }}(2,57)$. Зависимость между ВРП на душу населения ПФО и инвестиционными факторами выражается следующим уравнением регрессии:

$$
Y_{\text {ПФ }}=-98273,4+3,0^{*} x_{1}+981,8^{*} x_{2^{\prime}}
$$

где $Y_{\text {пфо }}$ - ВРП на душу населения ПФО, рублей;

$x_{1}$ - Инвестиции в основной капитал на душу населения ПФО, рублей.

$x_{2}$ - Сумма поступивших иностранных инвестиций на душу населения в ПФО, долл. США.

Далее проведем отбор инновационных факторов, оказывающих наибольшее влияние на уровень ВРП на душу населения Нижегородской области и ПФО. В таблице 3 представлены исходные данные для построения модели регрессии, выражающей зависимость между
ВРП на душу населения Нижегородской области, ПФО и инновационными факторами развития региона за период с 2011 по 2018 гг.

Как можно заметить из таблицы, динамика всех показателей инновационного развития в течение рассматриваемого периода была различна. Однако значения всех показателей по итогам 2018 года значительно превышали значения 2011 года.

Результаты корреляционного анализа для выявления тесноты связи между инновационными факторами региона и уровнем ВРП на душу населения Нижегородской области и ПФО представлены в таблице 4.

Корреляционный анализ данных факторов показывает, что ВРП области на душу населения Нижегородской области имеет прямую связь со всеми рассматриваемыми факторами инновационного развития региона. Однако тесную связь результирующий показатель имеет с фактором X4 (коэффициент корреляции $\left.r_{y \times 4}=0,955\right)$ и с фактором X6 (коэффициент корреляции $\left.r_{y \times 4}=0,977\right)$. Это

Таблица 3

Исходные данные для построения модели регрессии, выражающей зависимость между ВРП на душу населения Нижегородской области и ПФО и инновационными факторами за период с 2011 по 2019 гг.

(составлено автором)

\begin{tabular}{|c|c|c|c|c|c|c|c|c|}
\multirow{2}{*}{ Период } & \multicolumn{2}{|c|}{ ВРП на душу населения, руб. Ү } & \multicolumn{2}{|c|}{$\begin{array}{c}\text { Затраты на научные исследо- } \\
\text { вания и разработки на душу } \\
\text { населения, руб., Х4 }\end{array}$} & $\begin{array}{c}\text { Численность персонала, занятого } \\
\text { научными исследованиями и } \\
\text { разработками, чел., Х5 }\end{array}$ & \multicolumn{2}{|c|}{$\begin{array}{c}\text { Объем инновационных } \\
\text { товаров, работ, услуг на душу } \\
\text { населения, руб., Х6 }\end{array}$} \\
\cline { 2 - 10 } & $\begin{array}{c}\text { Нижегород- } \\
\text { ская обл. }\end{array}$ & ПФ0 & $\begin{array}{c}\text { Нижегород- } \\
\text { ская обл. }\end{array}$ & ПФ0 & $\begin{array}{c}\text { Нижегород- } \\
\text { ская обл. }\end{array}$ & ПФ0 & $\begin{array}{c}\text { Нижегород- } \\
\text { ская обл. }\end{array}$ & ПФо \\
\hline 2011 & 196792,5 & 236240,2 & 10995,2 & 3053,0 & 39902,0 & 101579,0 & 39750,3 & 26230,1 \\
\hline 2012 & 255722,7 & 263976,2 & 13533,1 & 3666,4 & 40882,0 & 114204,0 & 59006,8 & 31929,5 \\
\hline 2013 & 281581,1 & 284810,4 & 13187,6 & 3839,9 & 41513,0 & 114013,0 & 60848,0 & 37951,6 \\
\hline 2014 & 308152,1 & 308995,4 & 17892,3 & 4258,9 & 39703,0 & 107656,0 & 45827,4 & 39695,3 \\
\hline 2015 & 338304,4 & 339075,0 & 20117,8 & 4652,2 & 39961,0 & 107679,0 & 55695,4 & 40401,7 \\
\hline 2016 & 356725,8 & 348226,8 & 23938,3 & 4984,8 & 41427,0 & 104304,0 & 53418,5 & 41107,5 \\
\hline 2017 & 388808,8 & 372653,7 & 23552,0 & 5465,7 & 40404,0 & 104885,0 & 94979,2 & 47579,5 \\
\hline 2018 & 410365,0 & 392652,4 & 24000,7 & 5607,2 & 40819,0 & 104916,0 & 95618,1 & 60505,7 \\
\hline
\end{tabular}

Таблица 4

Результаты корреляционного анализа тесноты связи между инновационными факторами и ВРП на душу населения Нижегородской области и ПФО

(составлено автором)

\begin{tabular}{|c|c|c|c|}
\hline Регион & $\begin{array}{c}\text { Затраты на научные исследо- } \\
\text { вания и разработки на душу } \\
\text { населения, руб., } \\
\text { Х4Y }\end{array}$ & $\begin{array}{c}\text { Численность персонала, занятого научны- } \\
\text { ми исследованиями и разработками, чел., } \\
\text { X5Y }\end{array}$ & $\begin{array}{c}\text { Объем инновационных товаров, } \\
\text { работ, услуг на душу населения, руб., } \\
\text { Х6Y }\end{array}$ \\
\hline Нижегородская область & 0,955 & 0,196 & 0,977 \\
\hline ПФ0 & 0,995 & $-0,301$ & 0,928 \\
\hline
\end{tabular}


свидетельствует о том, что при увеличении значений данных показателей инновационной активности, произойдет увеличение объема ВРП на душу населения. Фактор X5 (численность персонала, занятого научными исследованиями и разработками) имеет слабую связь с зависимой переменной $\left(r_{y \times 5}=0,196\right)$, а следовательно, он не может быть включен в модель регрессии. Инновационный фактор X5 не оказывает значительного влияния на ВРП на душу населения, как на один из показателей социально-экономического развития региона.

ВРП области на душу населения ПФО как и у Нижегородской области имеет прямую и тесную связь с фактором X4 (коэффициент корреляции $\left.r_{y \times 4}=0,995\right)$ и с фактором X6 (коэффициент корреляции $r_{y \times 4}=0,928$ ) Это свидетельствует о том, что при увеличении значений данных показателей инновационной активности произойдет увеличение объема ВРП на душу населения. Фактор X5 (численность персонала, занятого научными исследованиями и разработками) имеет слабую и обратную связь с зависимой переменной $\left(r_{y \times 5}=-0,301\right)$, а следовательно, данный фактор не может быть включен в модель регрессии.

Исходя из данных, можно заметить, что $F_{\text {крит }}=(0,05 ; 2 ; 8-$ $2-1)=5,79$, а $F_{\text {расч }}(520,08)$, поэтому уравнение регрессии является значимым. Параметры $a_{4}$ и $a_{6}$ являются статистически значимыми и должны быть включены в модель линейной регрессии, так как $t_{a 4}(5,85)>t_{\text {крит }}(2,57), t_{a 6}(9,3)>$ $t_{\text {крит }}(2,45)$.

Зависимость между ВРП на душу населения Нижегородской области и статистически значимыми инновационными факторами выражается следующим уравнением линейной регрессии:

$$
Y_{\text {Ниж. }}=35972,7+5,3^{*} x_{4}+3,2 * x_{6},
$$

где $Y_{\text {Ниж. }}$ ВРП на душу населения Нижегородской области, рублей;

$x_{4}$ - затраты на научные исследования и разработки на душу населения, рублей;

$x_{6}$ - объем инновационных товаров, работ, услуг на душу населения, рублей.

Оценим значимость модели и ее параметров. Уравнение регрессии является значимым, так как $F_{\text {расч }}(604,43)$ $>F_{\text {крит }}(5,79)$. Параметры $a_{4}$ и $a_{6}$ являются статистически значимыми и должны быть включены в модель линейной регрессии, так как $t_{a 4}(8,8)>t_{\text {крит }}(2,57), t_{a 6}(2,76)>t_{\text {крит }}(2,45)$.

Зависимость между ВРП на душу населения ПФО и статистически значимыми инновационными факторами выражается следующим уравнением линейной регрессии:

$$
Y_{\text {пФ० }}=61132,5+46,4^{*} x_{4}+1,2^{*} x_{6^{\prime}}
$$

где Ү - ВРП на душу населения ПФО, рублей;

$x_{4}$ - затраты на научные исследования и разработки на душу населения, руб.;

$x_{6}$ - объем инновационных товаров, работ, услуг на душу населения, руб.

Оценим совокупное влияние данных инвестиционных и инновационных факторов на результативный показатель. Можно сделать вывод, что уравнение регрессии является статистически значимым, поскольку $F_{\text {расч }}(3077,6)>F_{\text {крит. }}=(0,05 ; 4 ; 8-4-1)=9,12$. Так как $t_{\text {|а1| }}(4,77)>t_{\text {крит }}(3,18)$, р-значение $(0,018)<0,05, t_{|\mathrm{a} 2|}(6,29)$ $>t_{\text {крит }}(3,18)$, р-значение $(0,008)<0,05, t_{|a 4|}(20,99)>t_{\text {крит }}$ $(3,18)$, р-значение $(0,0002)<0,05, t_{|а 6|}(15,72)>t_{\text {крит }}(3,18)$, p-значение $(0,0006)<0,05$, то данные параметры являются статистически значимыми.

Уравнение совокупного влияния статистически значимых инвестиционных и инновационных факторов на показатель социально -экономического развития Нижегородской области выглядит следующим образом:

$$
Y_{\text {Ниж. }}=-111211,8+1,2^{*} x_{1}+226,8^{*} x_{2}+7,1^{*} x_{4}+2,6^{*} x_{6},
$$

По результатам регрессионного анализа для Приволжского федерального округа, можно сделать вывод, что уравнение регрессии является статистически значимым, поскольку $F_{\text {расч }}(2908,11)>F_{\text {крит }}(9,12)$. Так как $t_{a 1}(6,56)>t_{\text {крит }}(3,18)$, р-значение $(0,0072)<0,05, t_{a 2}$ $(3,42)>t_{\text {крит }}(3,18)$, р-значение $(0,04)<0,05, t_{a 4}(21,9)>t_{\text {крит }}$ $(3,18)$, р-значение $(0,0002)<0,05, t_{\text {а6 }}(4,68)>t_{\text {крит }}(3,18)$, р-значение $(0,02)<0,05$, то есть, данные параметры являются статистически значимыми.

Уравнение совокупного влияния статистически значимых инвестиционных и инновационных факторов на показатель социально -экономического развития ПФО выглядит следующим образом:

$$
Y_{\text {пФ० }}=26728,79+0,62^{*} x_{1}+143,79 * x_{2}+41,26^{*} x_{4}+0,82^{*} x_{6},
$$

В таблице 5 представлены уравнения регрессии, выражающие зависимость ВРП на душу населения Нижегородской области от инвестиционных и инновационных факторов развития региона.

Коэффициент регрессии в линейной модели показывает, на сколько абсолютных единиц в среднем изменится результативный показатель при изменении показателя фактора на одну абсолютную единицу. Так, рост всех показателей инвестиций и инноваций по Нижегородской области приводит к росту ВРП на душу населения.

Коэффициент регрессии $a_{1}$ в уравнении регрессии, выражающей зависимость между ВРП на душу населе- 
Таблица 5

Результаты построения моделей зависимости социально-экономического развития Нижегородской области от инвестиционных и инновационных факторов

(составлено автором)

\begin{tabular}{|c|c|c|c|c|c|c|c|c|c|c|}
\hline \multirow{2}{*}{$\begin{array}{c}\text { Группа независи- } \\
\text { мых факторов }\end{array}$} & \multirow{2}{*}{ Уравнение модели } & \multicolumn{5}{|c|}{ Коэффициенты модели } & \multicolumn{4}{|c|}{ Коэффициенты эластичности } \\
\hline & & $b$ & $a_{1}$ & $a_{2}$ & $a_{4}$ & $a_{6}$ & $\vartheta_{1}$ & $\vartheta_{4}$ & $\vartheta_{6}$ & \\
\hline $\begin{array}{l}\text { Инвестиционные } \\
\text { факторы }\end{array}$ & $Y_{\text {Ниж. }}=34903,5+6,5^{*} x_{1}-652,9^{*} x_{2}$ & 34903,5 & 6,5 & $-652,9$ & - & - & 147,6 & $-58,6$ & - & - \\
\hline $\begin{array}{l}\text { Инновационные } \\
\text { факторы }\end{array}$ & $Y=35972,7+5,3^{*} x_{4}+3,2^{*} x_{6}$ & 35972,7 & - & - & 5,3 & 3,2 & - & - & 30,8 & 57,9 \\
\hline $\begin{array}{l}\text { Инвестиционныеи } \\
\text { инновационные } \\
\text { факторы }\end{array}$ & $\begin{array}{l}Y_{\text {Ниж. }}=-111211,8+1,2^{*} x_{1}+226,8^{*} \\
x_{2}+7,1^{*} x_{4}+2,6^{*} x_{6}\end{array}$ & $-111211,8$ & 1,2 & 226,8 & 7,1 & 2,6 & 27,6 & 20,4 & 41,3 & 45,7 \\
\hline
\end{tabular}

ния Нижегородской области от инвестиционных факторов, показывает, что на 6,5 рублей увеличится объем ВРП на душу населения Нижегородской области при увеличении инвестиций в основной капитал на душу населения на 1 рубль. Исследуя уравнение регрессии, выражающее влияние группы инновационных факторов на результативный показатель, следует отметить, что при увеличении на 1 рубль затрат на научные исследования и разработки на душу населения, а также объема инновационных товаров, работ и услуг, объем ВРП на душу населения Нижегородской области увеличится на 5,3 и 3,18 рублей, соответственно. При исследовании совокупного влияния отобранных инвестиционных и инновационных факторов на уровень социально-экономического развития региона, можно сделать следующие выводы: при увеличении на 1 рубль инвестиций в основной капитал на душу населения, затрат на научные исследования и разработки на душу населения, а также объема инновационных товаров, работ и услуг на душу населения, объем ВРП на душу населения Нижегородской области увеличится на 1,2, 7,1 и 2,6 рублей, соответственно. При увеличении на 1 долл. США суммы поступивших иностранных инвестиций, ВРП на душу населения Нижегородской области увеличится на 226,8 рублей.

Изменения отдельных факторов в правой части уравнения по-разному влияют на величину ВРП на душу населения. Чувствительность ВВП к изменению отдельных факторов измеряется с помощью коэффициента эластичности, который рассчитываются согласно формуле:

$$
\ni=\mathrm{a}_{i} * \frac{X_{i} \text { cр. }}{\text { ВРП на душу населения ср. }} * 100 \%
$$

где $i$ - обозначает один из независимых факторов;

$a_{i}-$ коэффициенты в уравнении, соответствующие фактору $i$;

$X_{i \text { ср }}$ - среднее значение соответствующего фактора в течение всего периода анализа;
ВРП на душу населения ср - среднее значение ВВП за весь период анализа.

Результаты расчета значений коэффициентов эластичности ВРП на душу населения Нижегородской области представлены в таблице 5. Коэффициент эластичности в уравнении регрессии, показывающей влияние инвестиционных факторов на ВРП на душу населения, свидетельствует о том, что при увеличении инвестиций в основной капитал на $1 \%$, ВРП на душу населения Нижегородской области в среднем увеличится на 147,6\%, что свидетельствует о значительном влиянии данного показателя на уровень социально-экономического развития региона. При увеличении суммы поступивших иностранных инвестиций на 1\%, ВРП на душу населения Нижегородской области в среднем изменится на 58,6\%, Коэффициенты эластичности в уравнении регрессии, свидетельствуют о том, что при увеличении изменении затрат на научные исследования и разработки, объемов инновационных товаров, работ, услуг на душу населения на 1\%, объем ВРП на душу населения в среднем изменится на $30,8 \%$ и 57,9\%, соответственно. Исходя из итоговой модели регрессии, можно сделать следующий вывод. При изменении инвестиций в основной капитал на 1\%, на 27,6\% в среднем изменится ВРП на душу населения Нижегородской области. При изменении суммы поступивших иностранных инвестиций на 1\%, на 41,3\% в среднем изменится ВРП на душу населения Нижегородской области. При изменении затрат на научные исследования и разработки на $1 \%$ и при увеличении на $1 \%$ объемов инновационных товаров, работ и услуг на одного человека, ВРП на душу населения увеличится на 45,7\%.

В таблице представлены уравнения регрессии, выражающие зависимость ВРП на душу населения Приволжского федерального округа от инвестиционных и инновационных факторов развития региона.

Коэффициент регрессии $a_{1}$ в уравнении регрессии, выражающей зависимость между ВРП на душу населения ПФО от инвестиционных факторов, показывает, что на 3 рубля увеличится объем ВРП на душу населения 
Результаты построения моделей зависимости социально-экономического развития ПФО от инвестиционных и инновационных факторов

(составлено автором)

\begin{tabular}{|c|c|c|c|c|c|c|c|c|c|c|}
\hline \multirow{2}{*}{$\begin{array}{l}\text { Группа независи- } \\
\text { мых факторов }\end{array}$} & \multirow{2}{*}{ Уравнение модели } & \multicolumn{5}{|c|}{ Коэффициенты модели } & \multicolumn{4}{|c|}{ Коэффициенты эластичности } \\
\hline & & $b$ & $a_{1}$ & $a_{2}$ & $a_{4}$ & $a_{6}$ & $\vartheta_{1}$ & $\vartheta_{4}$ & $\Theta_{6}$ & \\
\hline $\begin{array}{l}\text { Инвестиционные } \\
\text { факторы }\end{array}$ & $Y_{\text {пю0 }}=-98273,4+3,0^{*} x_{1}+981,8^{*} x_{2}$ & $-98273,4$ & 3,0 & 981,8 & - & - & 70,2 & 60,7 & - & - \\
\hline $\begin{array}{l}\text { Инновационные } \\
\text { факторы }\end{array}$ & $Y_{\text {по0 }}=61132,5+46,4^{*} x_{4}+1,2^{*} x_{6}$ & 61132,5 & - & - & 46,4 & 1,2 & - & - & 64,7 & 16,1 \\
\hline $\begin{array}{l}\text { Инвестиционныеи } \\
\text { инновационные } \\
\text { факторы }\end{array}$ & $\begin{array}{l}Y_{\text {по0 }}=26728,8+0,6^{*} x_{1}+143,8^{*} x_{2} \\
+41,3^{*} x_{4}+0,8^{*} x_{6}\end{array}$ & 26728,8 & 0,6 & 143,8 & 41,3 & 0,8 & 14,5 & 8,9 & 57,6 & 10,7 \\
\hline
\end{tabular}

ПФО при увеличении инвестиций в основной капитал на душу населения на 1 рубль. Коэффициент а_2 показывает, что на 981,8 рублей увеличится объем ВРП на душу населения ПФО при увеличении суммы поступивших иностранных инвестиций на душу населения на 1 долл. США. Исследуя уравнение регрессии, выражающее влияние группы инновационных факторов на результативный показатель, следует отметить, что при увеличении на 1 рубль затрат на научные исследования и разработки на душу населения, а также объема инновационных товаров, работ и услуг, объем ВРП на душу населения ПФО увеличится на 46,4 и 1,2 рубля, соответственно. При исследовании совокупного влияния отобранных инвестиционных и инновационных факторов на уровень социально-экономического развития, можно сделать вывод о том, что при увеличении на 1 рубль инвестиций в основной капитал на душу населения, затрат на научные исследования и разработки на душу населения, объема инновационных товаров, работ и услуг на душу населения, объем ВРП на душу населения ПФО увеличится на 14,5, 57,6 и 10,7 рублей, соответственно. Кроме того, при увеличении на 1 долл. США суммы поступивших иностранных инвестиций на душу населения, ВРП на душу населения в среднем увеличится на 8,9 рублей.

Коэффициент эластичности в уравнении регрессии, показывающей влияние инвестиционных факторов на ВРП на душу населения, свидетельствует о том, что при увеличении инвестиций в основной капитал на 1\%, ВРП на душу населения ПФО в среднем увеличится на 70,2\%. Это свидетельствует о значительном влиянии данного показателя на уровень социально-экономического развития. Также, при увеличении суммы поступивших иностранных инвестиций на $1 \%$ результативный показатель увеличится на 60,7\%. Коэффициенты эластичности в уравнении регрессии, показывающей влияние инновационных факторов на ВРП на душу населения ПФО, свидетельствуют о том, что при увеличении затрат на научные исследования и разработки, объемов инновационных товаров, работ, услуг на душу населения на
1\%, объем ВРП на душу населения в среднем изменится на $64,7 \%$ и $16,1 \%$, соответственно. Исходя из итоговой модели регрессии, можно сделать следующий вывод. На 14,5\% в среднем изменится ВРП на душу населения ПФО при изменении инвестиций в основной капитал на 1\%. При увеличении суммы поступивших иностранных инвестиций на душу населения на 8,9\%, на 57,6\%, в среднем, изменится ВРП на душу населения Нижегородской области. При изменении затрат на научные исследования и разработки на 1\% и при увеличении на $1 \%$ объемов инновационных товаров, работ и услуг на одного человека, ВРП на душу населения увеличится на $10,7 \%$.

Таким образом, в результате оценки зависимости между показателем социально-экономического развития региона (ВРП на душу населения) от инвестиционных, инновационных и совокупности данных факторов, были построены уравнения регрессии для Нижегородской области и Приволжского федерального округа в целом. По результатам отбора инвестиционных факторов, имеющих тесную связь с показателем социальноэкономического развития, были выбраны показатели - инвестиции в основной капитал на душу населения и сумма поступивших иностранных инвестиций на душу населения. Данные факторы оказывают наибольшее влияние на результативный показатель, как при исследовании Нижегородской области, так и ПФО в целом. Наибольшую тесноту связи с результативным показателем имеют такие инновационные факторы, как затраты на научные исследования и разработки на душу населения, а также объем инновационных товаров, работ, услуг на душу населения. Это также было доказано в результате отбора статистически значимых факторов. Кроме того, рассчитанные коэффициенты эластичности и коэффициенты моделей регрессии показали, что увеличение значений данных показателей приводят к существенному увеличению показателя социальноэкономического развития региона. Следовательно, при изучении влияния инвестиционных и инновационных 
факторов на уровень социально-экономического развития Нижегородской области и ПФО, было доказано,

что инвестиции и инновации являются основой социально-экономического развития региона.

\section{ЛИТЕРАТУРА}

1. Промышленный и инновационный потенциал Нижегородской области как основа развития экспортных возможностей и импортозамещения// Информационно-издательский проект Государственной Думы Федерального Собрания Российской Федерации [Электронный ресурс]. URL: http://vtr. dumaexpert.ru/nikitin/

2. Официальный сайт Правительства Нижегородской области [Электронный ресурс]: URL: https://government-nnov.ru/

3. Официальный сайт Федеральной службы государственной статистики [Электронный ресypc]. URL:http://www.gsk.ru

4. арбекова А.Б. Факторы влияния на социально-экономическое развитие регионов// Территория науки. 2018. № 3. С.97-103.

5. Минаев Ю.Н. Анализ факторов, влияющих на уровень социально-экономического развития региона // Вестник. 2016. №1. С.333-340.

(c) Шаповалова Вера Николаевна (gorchakmarina@mail.ru).

Журнал «Современная наука: актуальные проблемы теории и практики»

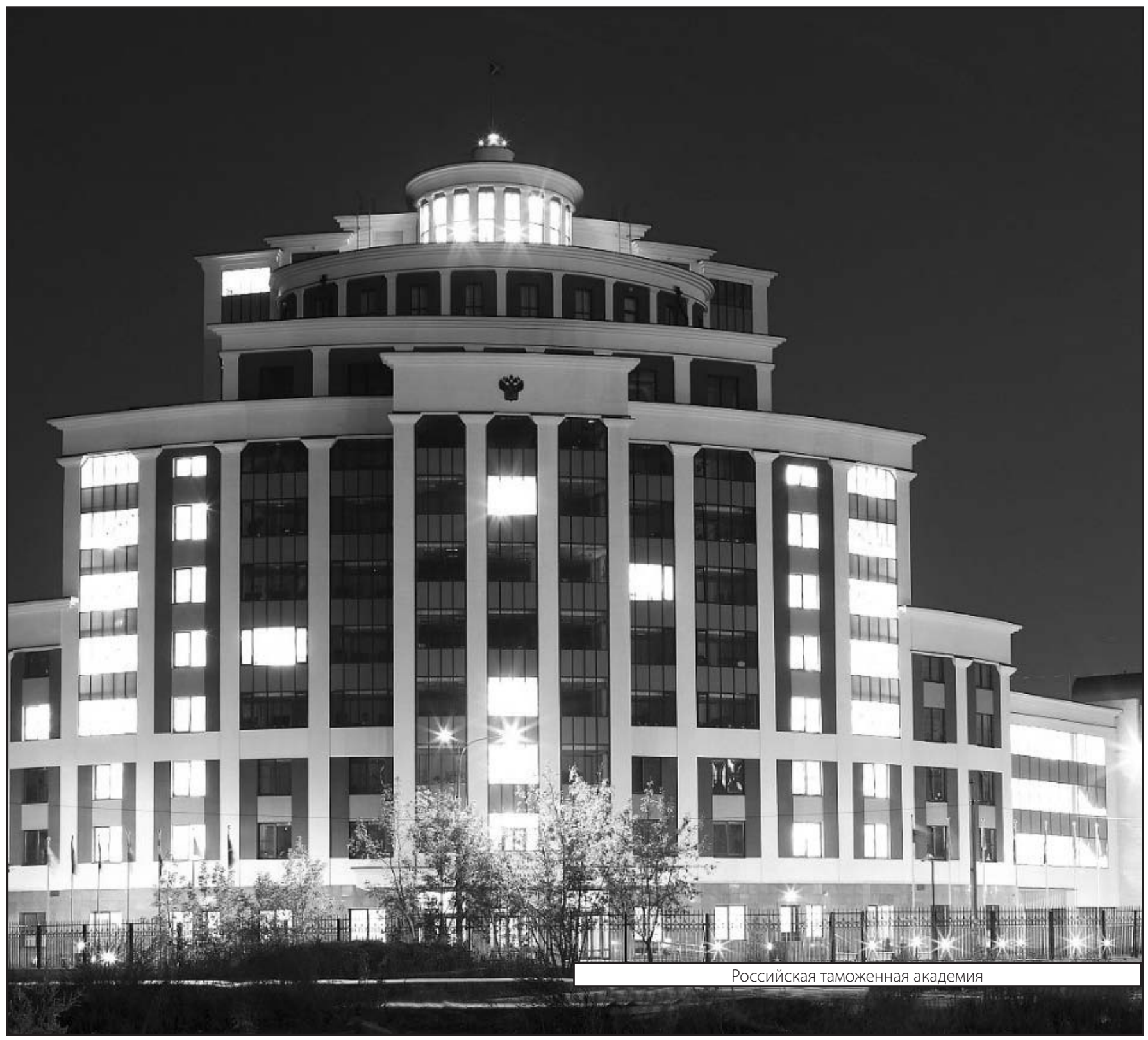

